\title{
Prácticas fotográficas, producción de saber $y$ manifestaciones de la violencia
}

\author{
Photographic Practices, Knowledge \\ Production and Expressions of Violence
}

\author{
María José Casasbuenas (Colombia) \\ mcasasbu@poligran.edu.co \\ Universidad Nacional de Colombia
}

\section{Resumen}

Este artículo desarrolla una reflexión sobre la naturaleza de las prácticas fotográficas y su relación con las manifestaciones de la violencia. Ante la consolidación de la fotografía como mecanismo de validación del saber, el texto problematiza la manera como, en las sociedades modernas, la fotografía contribuye a la reafirmación de formas de dominación y exclusión que trascienden en manifestaciones de violencia y transforman nuestras representaciones de los conflictos armados.

\begin{abstract}
The following article elaborates on a reflection of the nature of photographic practices and their connection with violence expressions. Since photography has consolidated as a mechanism to validate knowledge, the text argues about the way in which photography contributes to the reaffirmation of different forms of domination and exclusion in modern societies. The former escalate in violence expressions and transform our representation of the armed conflicts.
\end{abstract}

\section{FECHA DE RECEPCIÓN: FECHA DE REVISIÓN: APROBACIÓN: \\ 28 de mayo de 2012 29 de septiembre de 2012 1 de octubre de 2012}

Para citar este artículo / to cite this article

Casasbuenas, M. Prácticas fotográficas, producción de saber y manifestaciones de la violencia. Poliantea, 8(15), 45-72. 
- Prácticas fotográficas - María José Casasbuenas

Palabras clave: imagen, violencia,

fotografía, saber, conflictos armados, fotografía bélica.
Keywords: image, violence, photography, knowledge, armed conflict, belic photography. 


\title{
Prácticas fotográficas, producción de saber $y$ manifestaciones de la violencia
}

\author{
María José Casasbuenas \\ Candidata a Magíster en Estudios Culturales
}

\section{Introducción}

Cuando se piensa en la relación entre imagen y violencia mediada por la fotografía, automáticamente vienen a la mente un sinnúmero de imágenes de sucesos violentos e inhumanos que han sido registrados y representados, a través de esta tecnología, en las confrontaciones bélicas que han marcado la historia de la humanidad durante los últimos dos siglos. Desde mediados del siglo XIX, poco tiempo después de que la invención de Louis Daguerre fuera hecha pública en 1839 en Francia, los conflictos bélicos estarían entre las temáticas que se documentarían fotográficamente de manera continua.

Roger Fenton, fotógrafo británico, iniciaría esta tradición. En El valle de la sombra de la muerte (1855), imagen de la guerra de Crimea, se observa un paisaje desolado y sin referencias a lo humano, en el cual las balas de cañón se entremezclan con las rocas a lo largo de un camino sinuoso que se pierde en el horizonte. Esta imagen dista significativamente de las representaciones que consideramos como fotografía de guerra en la actualidad, tradición que se consolidaría en la primera mitad del siglo XX, y que configuraría una mirada particular sobre los conflictos, la legitimidad de la violencia, el lugar de la sociedad civil y de las víctimas, el posicionamiento del fotógrafo y el papel de los medios de comunicación masiva y de la información.

En este periodo, distintas figuras, tales como Robert Capa o Eugene Smith, encarnarían el ideal de reportero, su mirada sensible y su compromiso por 
mostrar las atrocidades de la guerra. La amplia difusión de sus imágenes, gracias a los magazines ilustrados, como Vu o Life, haría que la fotografía bélica emergiera como uno de los géneros centrales de la práctica fotográfica del siglo XX.

Evidentemente, no podemos negar la importancia que han tenido estas representaciones fotográficas y su papel fundamental en la visibilización de estas violencias en el campo social. ¿Quién puede, acaso, afirmar que, después de ver las impresionantes imágenes de los campos de exterminio nazi de Margaret Bourke-Withe, luego de la liberación en la Segunda Guerra Mundial, o de aquellas de los soldados estadounidenses en el campo de batalla realizadas por Larry Burrows en Vietnam, nuestra idea sobre la guerra y de las violencias no ha cambiado? No obstante, luego de la guerra del Golfo, nuestras representaciones de los conflictos armados han mutado y no todas las imágenes que se producen en este marco responden a la categoría de fotografía de guerra antes mencionada. Un ejemplo de ello serían las fotografías tomadas por los marines estadounidenses de los prisioneros de guerra en Abu Ghraib durante la invasión a
Irak en 2004. Y aquí creo justo y necesario hacer eco de las palabras de Susan Sontag (2004b):

[...] ¿la cuestión central no son las propias fotografías sino la revelación de lo ocurrido a los "sospechosos" arrestados por Estados Unidos? No: el horror mostrado en las fotografías no puede aislarse del horror del acto de fotografiar, mientras los perpetradores posan, recreándose, junto a sus cautivos indefensos.

Paradójicamente, la ausencia de humanidad que observamos en la imagen de Fenton recubre muchas de las imágenes que hoy en día consumimos de los conflictos bélicos, particularmente después de la introducción de la televisión y las nuevas tecnologías de la información y la comunicación que nos ofrecen imágenes en "tiempo real". Esta ausencia que en Fenton respondía a las posibilidades técnicas del momento histórico - Fenton utilizaba el proceso de colodión húmedo, que, además de requerir todo un andamiaje para su elaboración, no era una emulsión lo suficientemente sensible para el registro del movimiento-. En el caso de las guerras telerregistradas y transmitidas en la actualidad, deberíamos preguntarnos no por las posibilidades tecnológicas de registro 
de los dispositivos de captura de imágenes, sino más bien por el componente ideológico que rige estas representaciones: qué o quién determinan qué y cómo se visualizan los conflictos bélicos, por qué se parecen más a escenarios de videojuegos o de películas de ficción deshumanizadas que a escenarios donde día a día mueren cientos de seres humanos. En este sentido, las reflexiones sobre la representación elaboradas por Stuart Hall resultan enriquecedoras, pues pone de manifiesto que esta sensación de naturalización en la relación que establecemos con cierto tipo de signos, particularmente los de carácter visual, revelan no la transparencia y la "naturalidad" del lenguaje, sino la profundidad del hábito y la "casi universalidad" de los códigos en uso, que tiene por consecuencia el efecto (ideológico) de ocultar las prácticas de codificación que están presentes (2011, p. 7).

Ahora bien, en este espacio me gustaría revisar, desde una perspectiva crítica, otras prácticas fotográficas que, a mi modo ver, también han participado discretamente en la configuración de algunas violencias, que en la actualidad, experimentamos sutil, pero continuamente, violencias que se han encarnado en nuestros cuerpos, que se manifiestan en esquemas de percepción y de inclinaciones que configuran el campo social y nuestra experiencia situada de la realidad. En esta ocasión, quisiera referirme a las prácticas fotográficas articuladas con la producción de saber, y en especial, utilizadas ampliamente en el momento de la consolidación de las disciplinas académicas en el siglo XIX. Lo que se pretende es, por una parte, evidenciar las condiciones de posibilidad para que la fotografía se posicionara como una herramienta de registro y validación de ciertas formas de conocimiento $y$, por otra, evidenciar algunas formas de violencia implicadas en la práctica fotográfica, la cual, enmarcada en los discursos de producción del conocimiento — como la medicina, la antropología, la psiquiatría y el derecho-, ha contribuido a la consolidación y reproducción de formas de dominación y de exclusión en las sociedades modernas, en otras manifestaciones de la violencia.

Para iniciar, quisiera recordar algunos elementos que me parecen importantes antes de abordar la particular relación entre la fotografía y las emergentes disciplinas científicas en el siglo XIX, y para ello resultan 
valiosas las reflexiones del filósofo Michel Foucault.

Este filósofo se interesará por realizar un análisis/teoría del poder a partir de estudios críticos de carácter arqueológico y genealógico sobre algunas instituciones que emergen de los importantes cambios operados en las sociedades europeas del siglo XVIII y principios del XIX, particularmente en los nuevos Estados nacionales. Observará cómo las articulaciones entre las condiciones materiales de existencia de los individuos, los intereses académicos y científicos y el desarrollo del capitalismo como una nueva forma de producción propiciará el surgimiento de nuevas formaciones científico-jurídicas, nuevos instrumentos y técnicas del control, una nueva forma de ejercer el poder: un biopoder. Este elemento será constitutivo de las formas de gobierno que advienen con la modernidad, configuración cuya emergencia marcaría el umbral de las políticas actuales en Occidente, y que finalmente, a la vez, generaría unas condiciones de posibilidad de los modos como somos y nos entendemos actualmente como sujetos.

Para Foucault, el saber de un periodo histórico es constituido por el conjunto de los regímenes de enunciados posibles, regímenes que encuentran sus límites en lo visible y lo decible en un tiempo y un lugar determinado, y que resultan de tensiones y luchas que permiten que emerjan algunos enunciados y no otros. Además, este autor plantea:

[...] en toda sociedad, la producción del discurso está a la vez controlada, seleccionada y redistribuida por cierto número de procedimientos que tienen por función conjurar sus poderes y sus peligros, dominar el acontecimiento aleatorio y esquivar su pesada y temible materialidad (2002, p. 14).

Entre estos procedimientos de control sobre el discurso, Foucault identifica: la prohibición, la separación entre la locura y la razón y la voluntad de saber o de verdad que ha estado presente a lo largo de la historia de los hombres, pero que ha sufrido también singulares discontinuidades a lo largo del tiempo.

Esta voluntad de saber condiciona, por una parte, los objetos por conocer, las funciones y posiciones del sujeto conocedor, la configuración de la(s) mirada(s) particular(es) sobre la realidad, las inversiones materiales y técnicas para la producción del conocimiento y su función 
en una sociedad determinada. Además, esta voluntad de saber

[...] está sostenida y reforzada por una densa serie de prácticas e instituciones, muchas de ellas de carácter disciplinario y sobre todo íntimamente relacionada con las formas como ese saber se pone en práctica en el seno de una sociedad particular en la que es valorado, distribuido, repartido y en cierta forma atribuido (Foucault, 2002, p. 22).

De esta forma, las disciplinas que, en palabras de este autor, se definen como "un ámbito de objetos, un conjunto de métodos, un corpus de proposiciones consideradas verdaderas, un juego de reglas y de definiciones, de técnicas y de instrumentos" (2002 p. 33) son también una forma de control sobre el discurso, que, además, necesitan que "haya la posibilidad de formular indefinidamente nuevas proposiciones" (2002, p. 33), lo cual asegura su continuidad.

Ahora bien, Foucault identifica dos grandes rupturas en la episteme occidental: la primera en el siglo XVII, que inaugura lo que el denominará "la época clásica", y otra en el siglo XIX, que señala como el umbral de la modernidad, en la cual la redistribución en el orden del saber posibilita que emerja el hombre y se constituya como sujeto y a la vez como objeto de conocimiento; de esta forma propicia, las condiciones de posibilidad para el surgimiento de lo que denominará las ciencias del hombre: la medicina, las ciencias psi y las ciencias sociales. En este momento de la historia,

[...] la mirada no es ya reductora sino fundadora del individuo en su calidad irreductible. $Y$ por eso se hace posible alrededor de él un lenguaje racional. El objeto del discurso puede bien ser así el sujeto, sin que las figuras de la objetividad, sean por ello mismo modificadas (Foucault, 2004, p. 8).

Sin embargo, concebir las nuevas ciencias reguladoras del cuerpo (individual y social) del siglo XIX como un ejercicio negativo y represivo del poder sería no tener en cuenta uno de los aportes fundamentales de Foucault, a saber: la capacidad positiva y productiva de relación del poder con el saber. En el caso específico de la fotografía, en relación con las emergentes disciplinas científicas, la voluntad de saber no solo produjo nuevas formas de entender, interpretar y actuar sobre los objetos de conocimiento específicos de los campos científicos, 
en los que fue racional e instrumentalmente utilizada, sino que también esta relación sería fructífera para el desarrollo de la fotografía misma.

Ejemplo de ello serían las innovaciones, en el ámbito tecnológico, que introduciría Eadweard James Muybridge en 1877. Muybridge desarrolló el obturador mecánico que permitía captar las etapas del movimiento al disminuir de manera considerable los tiempos de exposición a milésimas de segundo, para responder al encargo realizado por el exgobernador de California, Leland Stanford, de fotografiar a Occident, uno de sus caballos de carrera. De esta manera, no solo se resolvió el interrogante sobre si los caballos a galope suspenden las cuatro patas en el aire en algún momento - lo que determinaría también el ganador de la apuesta hecha por el exgobernador al respecto-, sino que, además, ampliaría las posibilidades de registro del movimiento por medio del proceso fotográfico y produciría las condiciones de posibilidad para la emergencia del cine a finales de ese siglo.

Posteriormente, Muybridge se vinculará a la Universidad de Filadelfia, donde producirá un abundante e impresionante trabajo fotográfico sobre el movimiento (animal y humano), que sería publicado con el título Animal Locomotion, en 1887. Los ejercicios de Muybridge inspirarían a muchos investigadores en el campo de la anatomía y fisiología: el médico francés Étienne Jules Marey desarrollaría la cronofotografía, que le permitiría obtener en una sola placa las diferentes etapas secuenciales de un movimiento; también el fotógrafo Ottomar Anschütz desarrollaría experimentaciones similares en Polonia, solo por nombrar algunos personajes. Cabe aclarar que, aunque la fotografía fue utilizada en diferentes disciplinas en el siglo XIX, nos centraremos en aquellas relacionadas con el cuerpo y con los individuos, enmarcadas en las llamadas ciencias del hombre.

Ahora bien, en los trabajos que realizará Foucault, reconocerá como un elemento importante para la emergencia de estas disciplinas el surgimiento de una nueva racionalidad clínica y la paulatina medicalización de los diferentes ámbitos de la experiencia humana. Para ello, observa cómo la emergencia del saber clínico surge de una redistribución entre lo visible y lo invisible en el ámbito de la patología que está directamente ligada a lo que se 
enuncia, cómo se enuncia y lo que se calla en relación con la enfermedad (2004, p. 4). En este sentido, Foucault afirma:

[...] la relación de lo visible con lo invisible, necesaria a todo saber concreto, ha cambiado de estructura y hace aparecer bajo la mirada y en el lenguaje lo que estaba más acá y más allá de su dominio. Entre las palabras y las cosas, se ha trabado una nueva alianza que hace ver y decir (2004, p. 5).

Resalta cómo esta reorganización de lo visible surge de una mirada particular, consecuencia de la transformación y del desarrollo de la observación médica donde surgirán unos métodos específicos (de carácter positivo). Esta nueva mirada producirá un conjunto de signos (síntomas), que, al ser relacionados, configurarán "casos", que pueden ser organizados y analizados, estructurando así un conocimiento singular del enfermo que reconfigura la experiencia individual y social en torno a la salud y la enfermedad. En este sentido, es importante recordar el auge que tuvo el pensamiento positivista durante el siglo XIX en el contexto europeo, que consideraba solamente válidos o legítimos los conocimientos susceptibles de verificación y que surgieran de la aplicación del método científico. Esta forma de relacionarse con el conocimiento y legitimarlo impregnaría todas las prácticas y campos del saber, implementándose como la forma hegemónica para su producción. Así es como, para el ejercicio de la clínica, se propondrá una serie de protocolos que sistematizarán el ejercicio médico y su control: la observación, el registro y el archivo que permite la comparación entre los casos: la propuesta terapéutica.

De esta forma, con el surgimiento de la mirada clínica, apoyada fundamentalmente en la experiencia empírica visual y la descripción, también surgirá una nosopolítica específica y completamente novedosa en el siglo XVIII, que generará una serie de transformaciones importantes en la concepción de la enfermedad y en las prácticas de la salud e higiene que fueron paulatinamente articuladas al control de las poblaciones. Foucault señala cómo en este momento histórico "la salud, y el bienestar físico de la población en general, se convierte en uno de los objetivos esenciales del poder político" (p. 331), lo que constituye una perspectiva diferente, pues pretende no solo impactar 
un grupo específico de la sociedad -los excluidos, los enfermos pobres-, sino que busca el mejoramiento general de las condiciones de salud de todo el cuerpo social. Sin embargo, aunque la preocupación por la enfermedad y por los pobres esté profundamente relacionada con los imperativos del trabajo y las necesidades de la producción, el autor subraya que esto hace parte de otro proceso más general y que no solo responde a un simple desarrollo.

Este interés por el mejoramiento de las condiciones de la salud de los individuos está estrechamente relacionado con una transformación en el ejercicio del poder ${ }^{1}$, en el que, a diferencia del ejercicio de un poder soberano - que se fundamenta en el derecho de hacer morir o dejar vivir-, surge un ejercicio disciplinario del poder en el que "el poder está destinado a producir fuerzas, a hacerlas crecer y ordenarlas más que a obstaculizarlas, doblegarlas o destruirlas" (2007, p. 165), y que tiene en la anatomopolítica del

1 Foucault desarrolla el análisis sobre las trasformaciones del ejercicio del poder en La historia de la sexualidad (cap. V, pp. 161194). cuerpo humano ${ }^{2}$ y la biopolítica ${ }^{3}$ de la población dos polos entrelazados por todo un haz intermedio de relaciones (2007, p. 165).

De esta forma, en el siglo XVIII, además de las funciones que desde la Edad Media tiene el poder - gestionar la paz y la guerra-, se suma una nueva función: "[...] la reorganización de la sociedad como medio $^{4}$ de bienestar físico, de salud

2 Donde el cuerpo es asumido como una máquina que hay que educar, aumentar sus aptitudes, de carácter útil, y que se debe disciplinar.

3 Donde el cuerpo es entendido como el cuerpo-especie que sirve de soporte a los procesos biológicos: la proliferación, los nacimientos, la mortalidad, el nivel de salud, la duración de la vida y la longevidad, con todas las condiciones que pueden hacerlos variar, y que pueden ser sujeto de intervenciones y controles reguladores.

4 En la clase del 11 de enero de 1978, Foucault hace referencia a la noción de medio en relación con el problema de la circulación y de la causalidad en las ciudades. También observa la apropiación de tropos originados en las ciencias naturales al análisis del campo social, como por ejemplo el medio que tiene su origen en la mecánica y en la biología y que "se trata del soporte y el elemento de circulación de una acción". Resalta que, aunque la noción como tal no fue utilizada por arquitectos o urbanistas del siglo XVIII, sí considera que el esquema técnico está presente en el modo como urbanistas intentan reflejar y modificar el espacio urbano, y la incorporación del hospital en la tecnología moderna responde a esta lógica. En este sentido, el medio se constituye en "un elemento en cuyo interior se produce un cierre circular de los efectos y las causas", y de esta forma será concebido como un campo de intervención no de los individuos, sino de la población. 
óptima y de longevidad" (1999, p. 311). Acá, la noción de medio resulta fundamental, pues, aunque es un tropo que procede de la mecánica y la biología que define "un elemento en cuyo interior se produce un cierre circular de los efectos y las causas", es trasladado y operativizado paulatinamente en otros discursos, como el médico, y permitirá concebir la sociedad como un campo de intervención. Esta intervención se llevará a cabo mediante la policía, término que en el siglo XVII hace referencia a un conjunto de reglamentos y de instituciones múltiples que tienen como función afirmar el orden, canalizar el crecimiento de las riquezas, a partir de la reglamentación de la economía, y asegurar el mantenimiento de las condiciones de salud y de higiene ${ }^{5}$. De esta forma, se entiende, por ejemplo, por qué la medicina, más allá de preocuparse por las condiciones de salud de los individuos, ocupará un lugar representativo en el siglo XVIII en la

5 En las clases del 29 de marzo y 5 de abril de 1978, el autor profundizará en la policía como una tecnología característica de un nuevo arte de gobernar, y resalta que la policía en el siglo XVII estará relacionada con una preocupación por el mantenimiento de la vida, pero sobre todo por su mejoramiento; vivir pero vivir mejor: el bienestar (pp. 355-409). articulación de una economía analítica de la pobreza y el surgimiento de una policía general de salud.

Hay que tener en cuenta que este interés por las condiciones materiales de la existencia de los individuos está relacionado con la necesidad de mantener y preservar la "fuerza de trabajo", pero que también es efecto de aspectos y problemáticas económico-políticas del siglo XVIII en el contexto europeo: el crecimiento demográfico, la instauración del sistema de producción capitalista y la necesidad de integrar el crecimiento económico; lo que demandaría una nueva forma de gestionar y controlar los diferentes procesos sociales, dando como resultado el surgimiento de la población: sujeto y objeto de la política.

Así es como, en el siglo XVIII, surge una nueva noción del cuerpo -tanto de los individuos como del cuerpo social- como portador de nuevas variables relacionadas con su utilidad, sus posibilidades de intervención, de aprendizaje, de enfermedad o supervivencia, etc. Esta noción resulta particularmente novedosa, ya que, por primera vez,

[...] los rasgos biológicos de una población se convierten así en 
elementos pertinentes para una gestión económica, y es necesario organizar en torno a ellos un dispositivo que asegure su sometimiento, y sobre todo el incremento constante de la utilidad (1999, p. 333).

Del mismo modo, emergerá en el siglo XIX un concepto central de la estadística social: la noción de hombre medio, introducido por Adolphe Quetelet, astrónomo y naturalista belga, matemático y sociólogo, quien sería uno de los primeros en introducir los métodos estadísticos (de carácter cuantitativo) al campo sociológico, particularmente para el estudio de la criminalidad. El hombre medio no representaba a un individuo particular, sino los elementos comunes y regulares que "podían ser considerados como evidencia de determinadas leyes sociales"; en ese sentido, "constituía un ideal, no solamente de salud social, sino también de estabilidad y de belleza” (Sekula, 2003, pp. 151-153).

Ahora bien, debemos tener en cuenta las singularidades de la fotografía y del contexto en el cual emerge esta técnica en las primeras décadas del siglo XIX. Desde su invención, la fotografía, hecha pública en 1839 en la Academia de las Ciencias en Francia, se presentará como una herramienta eficaz para el registro fiel de la realidad y tendrá una amplia aceptación en las sociedades europeas. Esta invención marcará una ruptura importante con las anteriores formas de representación, ampliando de manera significativa el campo de lo visual en las sociedades modernas y transformando las miradas y las experiencias mediadas por los diferentes tipos de imágenes (Debray, 1994).

Esta nueva técnica de producción de imágenes mecanizada encontró un terreno propicio para su difusión y aplicación en el contexto europeo, ya que respondía, de manera satisfactoria, con las búsquedas y expectativas presentes en estas sociedades durante el siglo XIX, particularmente las relacionadas con el conocimiento científico del mundo de carácter positivista, así como con la confianza puesta en los artefactos producidos industrialmente. En su posicionamiento histórico, el retrato ocupará un lugar central entre las primeras aplicaciones de esta nueva tecnología. Heredero de la tradición retratista de la pintura clásica, del fisionotrazo y el retrato en miniatura, el retrato encontró un terreno propicio para su desarrollo gracias a las nacientes clases medias 
y burguesas que lo adoptaron como forma distintiva de representación. La invención de la carte de visite por André-Adolphe-Eugène Disderi en 1854, y la rápida disminución de los costos de producción y consumo de fotografías hacia finales del siglo XIX, daría origen a la tradición de álbumes de familia como a los procesos de democratización y de industrialización de la práctica fotográfica. Su origen tecnológico ofreció un método satisfactorio para la representación de la realidad, acorde con la experiencia visual del mundo; esta experiencia de la imagen mecanizada y de carácter mimético consolidaría la idea de la objetividad fotográfica, idea que fundamentó, en gran medida, la concepción histórica y social de la fotografía y, por consiguiente, determinó muchas de las prácticas en las cuales ella ha participado.

Concebida como prueba irrefutable de la verdad, no solo obtuvo este estatus por los procedimientos tecnológicos de tipo físico-químico y mecánico utilizados en su producción, sino que su legitimización como representación objetiva de la realidad se debió - también- a su amplia utilización en instituciones de control social, como la policía, el manicomio, el hospital, la escuela y la familia, los medios de información y de comunicación, que constituyen, en términos de Althusser, los aparatos represivos e ideológicos del Estado (1988). En este sentido, su uso en disciplinas, como la antropología, la medicina, la psiquiatría y la criminología a finales del siglo XIX, convirtió a la fotografía en una herramienta para el conocimiento y reconocimiento del "otro": desconocido, exótico, diferente salvaje o anormal, para su representación en un lugar subordinado y para la consolidación de estereotipos a partir de nociones, como la raza, el género y la clase social, categorías atravesadas por relaciones de poder (Tagg, 2005), que fueron y siguen siendo hoy operativas en el ejercicio de diferentes violencias.

Una aclaración antes de continuar: la relación particular que establece la representación fotográfica entre el referente y la imagen, puesto que su condición indicial fue un elemento central para que ella fuera considerada una prueba fidedigna. Sin embargo, y como lo argumenta John Tagg:

En un nivel más sutil, no obstante, tenemos que ver que cada 
fotografía es el resultado de distorsiones específicas, y en todos los sentidos significativas, que hacen que su relación con cualquier realidad anterior sea algo sumamente problemático, y plantean la cuestión del nivel determinante del aparato material y de las prácticas sociales dentro de las cuales tiene lugar la fotografía (2005, p. 8).

En este punto, considero necesario poner en evidencia una diferencia entre dos formas de producción de retratos en esta época: aquellos que la gente del común mandaba hacerse de sí y aquellos producidos en instituciones disciplinarias y de control. En el primero de los casos, los retratos serán motivados por el deseo individual tanto de representación de una singularidad -fidedigna y concordante con la idea que tengo de mí mismocomo de posicionamiento social, y su producción estaba supeditada a un intercambio de carácter económico: pago para que se me retrate. Por el contrario, los retratos que se producirán en las instituciones estatales responderán a deseos diferentes: en ellos priman el deseo de aquellos que los realizan más que el de aquellos que son representados, y evidentemente no se dará ningún intercambio económico por su elaboración, al menos entre modelo y fotógrafo. Ambos, sin embargo, gracias a la invención de Disdéri, tendrían una amplia promoción en la segunda mitad del siglo XIX y circularían en diferentes contextos.

Así es como la fotografía, más que un medio para la representación de la violencia, ha sido un instrumento para su ejercicio, participando activamente en la producción de verdad, en la construcción de nociones, como las de verosimilitud y objetividad, para la representación de lo humano, de lo "otro", lo que contribuyó tanto a la normalización del cuerpo como de la psiquis $y$, por lo tanto, servido para su control y dominio. A continuación, observemos algunos ejemplos representativos del uso instrumental de esta técnica en diferentes campos del conocimiento.

Me gustaría comenzar por el inglés Francis Galton, familiar de Charles Darwin y profundamente influenciado por su teoría evolucionista de las especies. Galton se interesó en diferentes áreas del conocimiento, que abarcaron desde la botánica y la biología hasta la meteorología y la estadística. Asimismo, estaba sumamente interesado por las relaciones entre los 
aspectos psicológicos y morales con los aspectos fisionómicos, así como por la influencia de la herencia en/ sobre los individuos. Su trabajo, fuertemente influenciado por la frenología, pseudociencia propuesta por el alemán Franz Joseph Gall, y que buscaba determinar rasgos de la personalidad y del carácter de los individuos a partir de la medición y el estudio de la forma del cráneo, la cabeza y la cara, desembocaría en lo que Galton denominaría eugenesia, que significa 'buen nacido o buen reproducido' La eugenesia proponía el mejoramiento de las cualidades físicas y morales de la raza por medio de la selección artificial.

Galton descubrirá, en la fotografía, un método de análisis que le permitiría reconocer los rasgos fisionómicos constantes que estarían relacionados con ciertas patologías sociales o características psicológicas específicas. Para ello, recurriría a realizar retratos compuestos, primero, de criminales a partir de fotografías obtenidas de los archivos de centros penitenciarios, ${ }^{b}$ pero luego realizaría retratos compuestos de

6 Desde 1860 era recurrente en el Reino Unido la utilización de la fotografía por las fuerzas policiales, y, después de 1870, sería exigida a los centros de reclusión, donde se otros arquetipos sociales (judíos, estudiantes, enfermos psiquiátricos), convencido de que estos montajes fotográficos evidenciaban características comunes a los individuos, rasgos que serían un signo, sea de una patología, sea de otras particularidades. En palabras de Galton:

[...] el procedimiento fotográfico al que me referí permite obtener con precisión mecánica una imagen generalizada, una imagen que no representa a ningún hombre en concreto, sino a una figura imaginaria que posee los rasgos medios de un grupo determinado de hombres. Estos rostros ideales transmiten una sorprendente sensación de realidad. A primera vista, nadie dudaría de que corresponden a una persona real, y sin embargo, como ya he dicho, no es así: se trata de un retrato de un tipo, no de un individuo (2006, p. 65).

De esta forma, Galton pensaba que podría identificar y aislar rasgos de la apariencia que le permitirían catalogar, racionalizar y relacionar atributos de la personalidad humana con constantes de las condiciones sociales y las cualidades morales de los sujetos, para crear una tipología que serviría posteriormente para la

realizaban sistemáticamente retratos a los detenidos. 
producción de cierto tipo de individuos determinados biológicamente.

Para enmarcarse en el método científico y así poder hablar de una "estadística gráfica", su método consistía en dar una fracción de la exposición total de la placa a cada una de las fotografías seleccionadas para ser combinadas según la relación entre el número de imágenes superpuestas con el tiempo total de la exposición de la placa. También, Galton realizaría retratos compuestos alterando el orden de las imágenes individuales para así verificar que el orden de los factores no alterara el resultado en la imagen $y$, de esta forma, obtener una representación objetiva del "hombre medio". Galton recogería sus investigaciones de este tema en la obra Investigaciones sobre las facultades humanas y su desarrollo, publicada en 1883.

Sin embargo, Galton no fue el único en desarrollar este tipo de montajes y de apoyarse en el sustrato de objetividad que rodeaba la fotografía. El francés Arthur Batut realizaría numerosos experimentos con esta técnica y exaltaría sus ventajas para la producción del tipo, de una familia, de una tribu o de una raza. Luego de explicar su método dirá:
Así pues, obtendremos una fotografía en la que todos los accidentes que modifican el tipo de la raza, en la que todas las notas que marcan la individualidad habrán desaparecido y en la que solo habrá permanecido los caracteres misteriosos que forman la unidad de la raza (2006, p. 94).

Según Allan Sekula (2003), Galton "pretendía articular un programa social a través de la educación. Este programa giraba en torno a una profunda biologización ideológica de las relaciones de clase existentes en Inglaterra" (p. 167); probablemente, esta afirmación también sea válida para Batut. No obstante, estas ideas sobre el control de la herencia y la posibilidad del mejoramiento selectivo de la raza serían apropiadas, en diferentes contextos, durante el siglo XX, y llevarían, por ejemplo, a sustentar los procesos de blanqueamiento en América Latina o la prohibición de matrimonios interraciales hasta 1967 en Estados Unidos. Evidentemente, este tipo de experimentaciones y concepciones sobre la vida humana parecerían un cuento de ficción hoy en día, pero fueron estas las que alimentaron las políticas de limpieza étnica e higiene racial promovidas por el régimen nazi en los años treinta, luego de lo 
cual las prácticas eugenésicas serían cuestionadas por considerarse racistas. En la actualidad, sin embargo, podemos observar prácticas que se relacionan directamente con propuestas eugenésicas, como el control de la natalidad en la República Popular China; otros muchos debates han surgido propiciados por la bioética en relación con la manipulación genética y microcelular, en la que se plantean preguntas relacionadas sobre si caben o responden a los principios de la eugenesia.

Evidentemente, este interés por la raza fue central en el siglo XIX, periodo de expansión colonial de las naciones europeas y momento en el cual se consolidarían estereotipos sobre las características tanto intelectuales como morales de aquellos que físicamente son diferentes. En este sentido, el retrato antropológico, más allá de representar las diferencias, constituye una representación del ejercicio del poder donde se ejerce un dominio simbólico (y material) sobre el cuerpo del "otro", dominio que contribuyó al establecimiento y mantenimiento de los poderes coloniales hasta ya avanzado el siglo XX, pues como lo afirma John Pultz: "[...] esas imágenes eran recordatorios del poder de los europeos: poder para poseer, sostener y mirar fotografías equivalía a una posesión simbólica de los cuerpos en ellas representadas" (2003, p. 26).

Un ejemplo de este tipo de imágenes lo constituyen los retratos de Carl Dammann. Realizados por encargo para la Sociedad Berlinesa de Antropología (Berliner Gesellschaft für Anthropologie), con los que elaborará álbumes etnográficos sobre tipos raciales - exóticos- existentes en diferentes latitudes del planeta. Estas fotografías serían de gran utilidad para el ejercicio de medir, comparar, definir y categorizar los cuerpos, ejercicio que desarrollarían de manera sistemática los antropólogos y fisiólogos de la época.

$\mathrm{Al}$ igual que en la práctica médica, para que la fotografía fuera considerada legítima y válida, en estos procesos de carácter científico, se fue implementado una serie de protocolos sobre la forma, las dimensiones y las poses en las que ellas deberían ser realizadas. El biólogo inglés T. H. Huxley, en 1869, sería uno de los primeros en proponer un método de toma para que fuera aplicado sistemáticamente en la recolección de imágenes de las diferentes razas que existían en el 
Imperio británico. Este método requería que los individuos estuvieran desnudos, parados al lado de una vara de medición con escala y se realzarían retratos frontales y de perfil en planos generales y medios planos. John Pultz, en su texto sobre fotografía del cuerpo (2003), afirma que es justamente "la pose frontal la que concede un sesgo científico a la fotografía $[\ldots]$ y sugiere un quiebre infranqueable y jerárquico entre el fotógrafo y sujeto"; de esta forma, se determinan posiciones y relaciones específicas de poder.

Otro caso ilustrativo del lugar de la fotografía en los procesos coloniales son las imágenes de Francis Frith y de los hermanos Zangaki. Sus imágenes de Medio Oriente son ejemplo de la mirada sobre lo diferente, lo "otro" que se forjó en Europa sobre la diferencia, muestra que representa el orientalismo en el sentido desarrollado por Edward Said (1990), es decir, una forma discursiva en la que se establecen las relaciones entre el Occidente (hegemónico) y el Oriente (exótico), donde emerge la frontera entre "ellos" diferentes y "nosotros". Estas fotografías, surgidas de una mirada controladora, funcionaron como documentos que mostrarían las diferencias raciales y morfologías anatómicas que determinarían las variaciones de carácter psicológico y, sobre todo, de índole moral, que evidenciaban su supuesta inferioridad y falta de civilización ante la mirada del espectador, del colonizador.

Muchos fotógrafos desarrollaron este tipo de retratos con estas mismas intenciones, a saber, identificarse a sí mismo y posicionarse jerárquicamente en relación con el "otro", y en casi todas ellas el procedimiento fue el mismo. Un retrato frontal sobrio e inexpresivo, un retrato sistemático que posibilitará la comparación, la jerarquización, su posesión en forma de archivo. Las fotografías de indígenas norteamericanos realizados por David Barry y Edward Curtis, este último considerado uno de los padres de lo que, en la actualidad, se ha denominado la antropología visual, responden también a la misma voluntad de saber.

Volviendo nuevamente a la fotografía, en el contexto de las disciplinas médicas, son significativos los trabajos realizados en el hospital de la Pitie-La Salpêtrière, en la época del médico Jean-Martin Charcot. Reconocido por sus estudios sobre las enfermedades nerviosas, 
es considerado, junto con Guillaume-Benjamin-Amand Duchenne, padre de la psiquiatría y la neurología moderna; ambos recurrirían a la utilización de la fotografía como herramienta de investigación y como prueba en sus experimentaciones.

En 1862, Charcot es trasladado a La Salpêtrière, el hospital general de las mujeres, así como el mayor auspicio de Francia. Allí comenzaría su interés por las patologías psicológicas y desarrollaría las célebres lecciones de los martes a partir de 1882, sesiones en que se presentaban sus observaciones y los avances de sus investigaciones y donde confluían no solamente personas interesadas en el campo médico (Freud fue uno de sus asistentes en 1885-1886), sino personajes de la vida pública parisina. En estas sesiones, Charcot hacía demostraciones, entre otras, sobre las posibilidades de la hipnosis para la cura de ciertas patologías, particularmente la que denominaría posteriormente como histeria.

Es claro que el estudio de los comportamientos humanos y de las patologías de carácter psicológico demandaría otros métodos de trabajo que distarían de la fisiología y la anatomía, pero que otorgarían a la observación un papel central. Charcot promovería el método anatomoclínico, que él mismo definiría como

[...] el compromiso con los objetivos fisiológicos y esencialistas, en el estudio de las enfermedades nerviosas: aunque no podamos ver cómo funciona un cerebro, podemos descubrir los efectos provocados por las alteraciones de su funcionamiento gracias a los síntomas corporales, y por lo tanto diagnosticarlas (citado por DidiHuberman, 2007, p. 35).

Es de esta forma como la fotografía resultaría un recurso valioso en las investigaciones de Charcot, recurso que sería no solamente útil como herramienta experimental, sino que contribuiría tanto a la construcción de un archivo científico como a la transmisión de esos conocimientos. Así es como, en este momento, "el acto de ver [...] se convierte no solo en probatorio de lo que se observa, e incluso de aquello que, en tiempo normal, sería invisible o apenas vislumbraríamos, sino también susceptible de previsión" (DidiHuberman, 2007, p. 50). Será tal el reconocimiento y valoración de los beneficios que este tipo de representaciones tiene para el desarrollo del saber psiquiátrico, que, a partir de 1875 , se crearía el servicio fotográfico en el interior del hospital bajo 
la responsabilidad de Paul Regnard, y posteriormente estas imágenes serían publicadas como la Iconografía fotográfica de la Salpêtrière. En esta recopilación de fotografías, pueden observarse los diferentes momentos de la crisis histérica como las diferentes actitudes que son recurrentes en ella. Evidentemente, no sobra subrayar que esta patología fue considerada, en sus inicios, una enfermedad propiamente femenina, de ahí que todas las imágenes sean de mujeres, teniendo a Agustine en un lugar preponderante como caso representativo de la histeria.

En esta misma línea, estuvieron encaminados los experimentos realizados por Guillaume Duchenne, también conocido como Duchenne de Bologne, quien se interesó por los usos terapéuticos de la electricidad en experimentos anatómicos, fisiológicos y psicológicos. En su libro Mecanismo de la fisionomía humana o análisis electrofisiológico de las pasiones aplicable a la práctica de las artes plásticas, recogerá sus experimentaciones sobre individuos con parálisis facial a quienes les aplicará descargas eléctricas controladas para el estudio de los movimientos musculares que están en el origen de los gestos y las expresiones corporales.
Sin embargo, estos dos médicos franceses no fueron los primeros ni los únicos en haber utilizado la fotografía en el campo de las enfermedades mentales. El doctor inglés Hugh Welch Diamond, en 1856, ya había iniciado experimentaciones fotográficas en el Surrey County Lunatic Asylum, observaciones que presentaría en el informe La peculiar aplicación de la fotografía al esclarecimiento de la locura. En este texto inaugural, el doctor Diamond reconocía en la fotografía clínica tres importantes funciones: 1) actuaba como auxiliar del tratamiento, pues la elaboración de los retratos tenía efectos en los mismos pacientes, 2) permitía una documentación permanente para la orientación médica y el análisis fisionómico y 3) la fotografía era el "arte de la verdad", su registro perfecto y fidedigno era el medio más propicio para reproducir todas las formas y estructuras que buscaba esclarecer y explicar la ciencia (Tagg, 2005, pp. 103-104).

Ahora bien, la fotografía resultaría también una herramienta privilegiada para el ejercicio administrativo $y$ judicial en las ciudades; recordemos que, en esta época, los procesos de industrialización generaron una importante migración hacia las 
ciudades, lo cual aumentó la pobreza, los conflictos y los problemas en el panorama urbano. En 1871, durante la Comuna de París, la fotografía resulta un elemento central para la identificación y la elaboración de los dosieres acusatorios de los individuos que habían participado en la revueltas. Además, el reconocimiento de los efectos que podían tener las imágenes fotográficas en la población hizo que se emitieran decretos que censuraban la circulación de fotografías emblemáticas que pudieran perturbar la paz pública, particularmente aquellas de los individuos que habían liderado y participado en las revueltas de mayo. Asimismo, en este momento, la fotografía comenzará a ser utilizada con fines propagandísticos, como en el caso de los fotomontajes realizados por Eugène Appert, quien, por encargo de las autoridades públicas, fue autorizado para fotografiar los prisioneros y recurrir al fotomontaje que justificara y legitimara el ejercicio represivo y violento de las autoridades.

A partir de este momento, se reconocería la utilidad de la fotografía para fines de identificación y se vincularía rápidamente a la institución policíaca, gracias a los aportes de Alphonse Bertillon. Este policía francés desarrollaría el método antropofotométrico como forma de reconocimiento individual al servicio del control criminal en París. Este método, presentado en 1882, consistía en la elaboración de fichas de filiación que contenían elementos identificatorios basados en la medición de partes del cuerpo y la cabeza, signos y marcas, como cicatrices lunares, tatuajes, etc., que ayudarían a la identificación de criminales reincidentes. Cada una de estas fichas tendría dos retratos fotográficos, uno de frente y uno de perfil, como ya era acostumbrado en el campo antropológico.

El interés de Bertillon residía en establecer un sistema para catalogar los rasgos invariables y permanentes en el individuo que sirvieran para su identificación, para lo cual necesitaría de la estandarización de las formas en las que se realizarían las mediciones y las fotografías de identificación como también la forma en que estas fichas de filiación se sistematizarían y organizarían en un archivo basado en la estadística, siendo la noción de "hombre medio", de Quetelet, central para su organización (Sekula, 2003, p. 159).

En su texto La fotografía judicial (1890), Bertillon hace una serie 
de reflexiones y recomendaciones sobre cómo deben hacerse estas fotografías para que tengan valor de prueba judicial, y dice:

[...] la finalidad no es más que una, y por lo tanto, resulta más fácil analizarla: producir una imagen más parecida posible, la que resulte más fácil de identificar en relación con el original [...] Resumiendo, podemos decir, que un retrato judicial apunta, según el caso, a la individualidad presente, pasada y futura del inculpado y que, a cada uno de estos momentos, deben corresponder: 1) Formas especiales para resolver el problema fotográfico. 2) Formas especiales para utilizarlo (p. 106).

En este texto, Bertillon destaca el valor de la fotografía de perfil en relación con la pose frontal y determina como "la única que debe utilizarse para las identificaciones pensando en un intervalo de tiempo amplio" (p. 108), y rechaza todo intento de retoque, que, en la época, era un procedimiento común en los estudios fotográficos, ya que, "cuando se trata de un retrato judicial [...] la exactitud se convierte en la primera y única cualidad" (p. 109). En este sentido, es importante resaltar la conciencia de Bertillon sobre el medio fotográfico, así como su afán por normalizar su uso en las prácticas policiales.
De esta forma, no solo surgirían las fichas de filiación -que están en la base de nuestros documentos de identidad-, sino, a su vez, tablas de láminas que contenían fragmentos de elementos faciales (orejas, ojos, bocas, nariz), reunidos bajo el rótulo de Tableau Synoptique des Traits Physiognomiques (1893), los cuales podrían servir para recomponer ilimitadamente diferentes tipos. El método de Bertillon tendría una gran acogida en las últimas décadas del siglo XIX e inicio del XX; no obstante, la gestión y administración de los archivos, así como la tarea de comparación que demandaba la aplicación de su método, se hicieron un poco obsoletos cuando el número de registros y fichas comenzó a aumentar. Sin embargo, el bertillonaje, conjugado con el uso de las huellas digitales como elementos identificatorios e identificadores, sigue siendo utilizado en los documentos de identidad, como la cédula y el pasaporte.

Al igual que Bertillon en Francia, el médico italiano Cesare Lombroso realizaría estudios sobre la criminalidad en esta misma época. Afirmaba que eran causas biológicas y físicas las que estaban en el origen de la criminalidad, de modo que el delito era 
concebido como el resultado de elementos genéticos, de carácter innato, que podían ser observables en ciertos rasgos fisionómicos, lo que se ha denominado determinismo biológico. Lombroso definirá que el delincuente es "un ser atávico que reproducía en su persona los feroces instintos de la humanidad primitiva y de los animales inferiores" (citado por Sekula, 2003, p. 163). Esta postura está más cerca de las ideas de Galton que de aquellas de Adolphe Bertillon, pues, este último tenía en cuenta la noción de medio o entorno social, particularmente la influencia del contexto urbano que, en cierta medida, actuaría sobre los individuos y su tendencia a prácticas delincuenciales.

Ahora bien, en este tipo de ejercicios fotográficos, podemos observar que, más allá de lo que las imágenes representan (mujeres locas, razas inferiores o salvajes, patologías de comportamiento, etc.), ellas nos indican la concepción que tenían de la fotografía, aspectos sobre las ideas y los intereses de quienes las producían, concepciones que estaban en concordancia con el discurso que operaban en la época y que condicionaban tanto a los sujetos que las producían como los sentidos de sus producciones fotográficas.
Parecería también que las motivaciones altruistas de perseguir la verdad del conocimiento justificaran los métodos y las acciones para su consecución. En los escritos de Charcot sobre sus investigaciones en la Salpêtrière, describe el protocolo clínico: clasificación, muestra, comparaciones, reconocimiento, diagnóstico, instrucciones terapéuticas. En uno de los fragmentos de las Obras completas de este médico, citado por Didi-Huberman (2007) sobre la invención de la histeria, nos ilustra cómo eran las consultas en este hospital:

Se sienta junto a una mesa vacía $y$ se hace venir al enfermo que se va a estudiar. Se le desnuda íntegramente. El interno lee una observación, el Maestro escucha atentamente. A continuación un largo silencio durante el cual observa, observa al paciente, mientras da golpecitos con una mano sobre la mesa. Los ayudantes, de pie, esperan ansiosos una palabra que los instruya. Charcot continúa callado. Después, ordena al paciente a que realice un movimiento, le hace hablar, pide que se busquen sus reflejos, que se explore su sensibilidad. Y de nuevo, se hace el silencio, el silencio misterioso de Charcot. Por fin hace venir a un segundo enfermo, lo examina al igual que su predecesor, requiere un tercero, y siempre sin articular palabra, los compara unos a otros (p. 37). 
¿Qué podrá sentir ese "otro" a quien se examina? ¿Qué podrá experimentar ese a quien se interpela por medio de una mirada escrutiñadora? En este caso particular, ha de recordarse que los pacientes eran todas mujeres y que los médicos, siempre hombres. ¿Qué decir de las sesiones fotográficas donde en medio de la escenografía del estudio fotográfico, con camas, pantallas y cortinas, se esperaba a que se produjeran las crisis de las enfermas para ser registradas y catalogadas?

Pocas veces pensamos en la violencia que conlleva el acto fotográfico en sí mismo. Susan Sontag (2006), en su ensayo Sobre la fotografía, afirma:

No obstante, hay algo de depredador en la acción de hacer una foto. Fotografiar personas es violarlas, pues se las ve como jamás se ven a sí mismas, se las conoce como nunca pueden conocerse; transforma las personas en objetos que pueden ser poseídos simbólicamente (p. 31).

En el caso de la utilización instrumental de la fotografía en el ámbito de la producción de saber, esta premisa es más que ilustrativa, pues es evidente que la singularización y objetualización de los individuos operada por medio de la práctica fotográfica, que para representar un "caso" ilustrativo de las diferentes patologías clínicas y sociales que emergen de esta nueva configuración de la mirada y de la racionalidad médica y judicial del siglo XIX, participará efectivamente en su control y, por lo tanto, en el lugar de subordinación que serán ubicados sujetos "otros" en el panorama social.

Para entender mejor la dimensión de la violencia, en estas prácticas, y su incidencia en las violencias actuales en lo cotidiano, considero que los conceptos de Pierre Bourdieu de poder y violencia simbólica son bastante pertinentes. Para Bourdieu (2000), la violencia simbólica es la capacidad de generar visiones y divisiones legítimas del mundo, categorías y posicionamientos jerárquicos a partir de las incorporaciones de taxonomías sociales incorporadas históricamente, "producto de un trabajo continuado de reproducción al que contribuyen unos agentes singulares $[\ldots]$ y unas instituciones: familia, iglesia, escuela, estado" (p. 50). Bourdieu resalta las interpretaciones que pueden conducir a pensar que este ejercicio de la violencia no conlleva efectos materiales y concretos que se inscriben sobre los cuerpos de los sujetos, 
ya que es común relacionar lo simbólico con lo espiritual o como contrapuesto a lo real. Sin embargo, este autor explica que la violencia y el poder simbólico operan de múltiples maneras a partir de categorizaciones y posicionamientos siempre arbitrarios donde

[...] los dominados aplican a las relaciones de dominación unas categorías construidas desde el punto de vista de los dominadores, haciéndolas parecer como naturales $[\ldots]$ en otras palabras, cuando los esquemas que pone en práctica para percibirse y apreciar a los dominadores (bajo/alto, masculino/ femenino, blanco/negro, etc.) son el producto de la asimilación de las clasificaciones, de ese modo naturalizadas, de las que su ser social es el producto (p. 51).

En este punto, es indispensable reconocer que las llamadas ciencias del hombre, hoy denominadas ciencias sociales y humanas, se han transformado significativamente a lo largo del siglo XX gracias a las posturas críticas y reflexivas sobre las prácticas de producción de conocimiento. Paradójicamente, y como nos lo recuerda Foncuberta (2010), "las mismas ciencias surgidas del esplendor del positivismo, que recurrían al método científico y la tecnología para apelar a la objetividad, fueron las primeras en dejar traslucir su ideología latente y sus prejuicios" (p. 67), en especial a partir de la reevaluación del método científico como el único legítimo y válido para la comprensión crítica de las dinámicas sociales. Del mismo modo, estas revisiones contribuyeron a la transformación de la concepción de la fotografía, al cuestionamiento de los estatutos de verdad y objetividad asignados en un primer momento a la imagen obtenida por medio de esta tecnología de visión.

Evidentemente, no podemos afirmar que las violencias actuales, en nuestro contexto, son el resultado de la utilización instrumental de la fotografía en las disciplinas modernas; sin embargo, considero que existen residuos de las categorías y formas de representación como de concepciones sobre la otredad que emergieron en la producción del saber en el siglo XIX europeo, residuos que continúan interviniendo y operando en nuestras relaciones sociales, en las formas que se representa "la otredad" y que, en la actualidad, circulan en diferentes contextos sociales. Solo basta pensar en las asociaciones que hacemos cotidianamente entre indio y ladrón, negro y perezoso, mujer e histeria, o dar 
un vistazo a los periódicos y los medios de comunicación para ver cómo son representados los musulmanes, los homosexuales, las lesbianas y las personas trans, las y los jóvenes, sujetos que continuamente se están presentando ya sea como incivilizados o salvajes, poco morales, feminizados, irresponsables y peligrosos.

Recordemos que la representación es una parte esencial del proceso mediante el cual se produce el sentido y se intercambia entre los miembros de una cultura (Hall, 1997, p. 2 ), y es por medio de ellas que se recrean, se refuerzan y se reproducen también los estereotipos que de sujetos "otros" se han construido históricamente, estereotipos que, a partir de rasgos característicos, "reducen, esencializan, naturalizan y fijan la diferencia" (Hall, 1997, p55.).

Estos estereotipos participan activamente en determinar un lugar de subordinación y de exclusión de ellos y ellas, sujetos "otros", excéntricos, diferentes. Por esto, resulta importante proponer una mirada crítica y una postura política sobre la violencia que conlleva hacer fotografías, más aún cuando estas se realizan en la producción de conocimientos sobre los "otros", pues estas imágenes no solo representan la realidad, sino que también la intervienen.

\section{Referencias}

Althusser, L. (1988). Ideología y aparatos ideológicos del Estado. Freud y Lacan. Buenos Aires: Nueva Visión [en línea]. Consultado el 10 de abril de 2010 en <http://www.nombrefalso.com.ar/index.php?pag=81>.

Batut, A. (2006/1887). La fotografía aplicada a la producción del tipo, de una familia, de una tribu o de una raza. En Naranjo, J. (ed.) Fotografía, antropología y colonialismo (pp. 92-101). Barcelona. Editorial Gustavo Gili.

Bertillon, A. (2006/1890). La fotografía judicial. En Naranjo, J. (ed.) Fotografía, antropología y colonialismo (pp. 102-111). Barcelona. Editorial Gustavo Gili.

Bourdieu, P. (2000). La violencia simbólica. En La dominación masculina (pp. 49-59). Barcelona: Anagrama.

Debray, R. (1994). Vida y muerte de la imagen. Historia de la mirada en Occidente. Barcelona: Paidós.

Didi-Huberman, G. (2007). La invención de la histeria. Charcot y la iconografía fotográfica de la Salpêtrière. Madrid: Cátedra. 
Fontcuberta, J. (2010) Eugenésicos sin fronteras. En La cámara de pandora (pp. 67-87). Barcelona: Editorial Gustavo Gili.

Foucault, M. (1977). Derecho de muerte y poder sobre la vida. En Historia de la sexualidad I. La voluntad de saber (pp. 161-194). México: Siglo XXI.

Foucault, M. (1999). La política de la salud en el siglo XVIII. En Estrategias de poder. Barcelona: Paidós Iberoamérica.

Foucault, M. (2002). El orden del discurso. Barcelona: Tusquets (Colección Fábula).

Foucault, M. (2004). El Nacimiento de la clínica. Una arqueología de la mirada médica (pról.). Buenos Aires: Siglo XXI.

Foucault, M. (2006). Seguridad, territorio y población. Curso del Collège de France (1977-1978). Buenos Aires: Fondo de Cultura Económica.

Galton, F. (2006/1878). Retratos compuestos. En Naranjo, J. (ed.) Fotografía, antropología y colonialismo. Barcelona: Editorial Gustavo Gili.

Hall, S. (1980). Codificar y decodificar [en línea]. Consultado el 10 de abril de 2011 en <http://www.mseg.
gba.gov.ar/ForyCap/cedocse/capacitacion $\% 20$ y\%20formacion/educacion/Codificar\%20y\%20Decodificar.\%20Stuart\%20Hall.pdf>.

Pultz, J. (2003). El siglo XIX: realismo y control social. En La fotografía $y$ cuerpo (pp. 13-35). Madrid: Akal.

Said, E. (1990). Introducción. En Orientalismo (pp. 19-49). Barcelona: Ib Jaldun.

Sekula, A. (2003). El cuerpo y el archivo. En Picazo, G. y Ribalta, J. (eds.) Indiferencia y singularidad (pp. 133200). Barcelona: Editorial Gustavo Gili.

Sontag, S. (2006). Sobre la fotografía. México: Alfaguara.

Sontag, S. (2004a). Ante el dolor de los demás. Madrid: Santillana.

Sontag, S. (2004b). Ante la tortura de los demás. El Malpensante, 55. Consultado el 1 de abril de 2011 en <http://www.elmalpensante.com/index.php?doc=display_ contenido\&id $=1114>$.

Tagg, J. (2005). El peso de la representación. Ensayos sobre fotografías e historias. Barcelona: Editorial Gustavo Gili. 